\title{
"Meu filho, minhas regras": o caso do Escola sem Partido em Belo Horizonte
}

\section{Leandro de Paula ${ }^{1}$ \\ João Victor Iglesias ${ }^{2}$}

\begin{abstract}
Resumo: No ano de 2019, o município de Belo Horizonte tornou-se a primeira capital brasileira a aprovar um projeto de lei baseado no movimento Escola sem Partido (ESP). Este artigo analisa em detalhe o processo desde a apresentação do projeto de lei, em 2017, até sua aprovação em primeiro turno, destacando os antagonismos performados na cena parlamentar. Sondamos os vínculos do ESP com a tese do "marxismo cultural" e sua transformação em ativo político no Brasil recente, analisando como grupos conservadores têm acionado novas concepções de sujeitos de direitos fundamentais. Metodologicamente, o trabalho se apoia nas ferramentas da análise de controvérsias públicas.
\end{abstract}

Palavras-chave: Escola sem Partido; marxismo cultural; guerras culturais

\section{"Mi hijo, mis reglas": el caso "Escola sem Partido"en Belo Horizonte}

Resumen: En 2019, Belo Horizonte se convirtió en la primera gran ciudad brasileña en aprobar un proyecto de ley basado en el movimiento Escola sem Partido (ESP). Este artículo analiza el proceso empezado con la presentación del proyecto de ley en 2017, hasta su aprobación en la primera ronda, destacando los antagonismos presentes en el ambiente parlamentario. Examinamos las conexiones de ESP con la tesis del "marxismo cultural" y su transformación en un activo político en el Brasil reciente, analizando cómo los grupos conservadores han planteado nuevas ideas sobre temas de derechos fundamentales. El artículo se basa en las herramientas metodológicas propuestas por el análisis de las controversias públicas.

Palabras clave: Escola sem Partido; marxismo; guerras culturales

"My son, my rules": the "Escola sem Partido" case in Belo Horizonte

Abstract: In 2019, Belo Horizonte became the first big Brazilian city to pass a bill based on the Escola sem Partido movement (ESP). This paper deals with the process that took place since the

\footnotetext{
${ }^{1}$ Leandro de Paula Santos. Doutor em Comunicação e Cultura pela UFRJ (2016). Professor Adjunto da UFBA, no Instituto de Humanidades, Artes e Ciências (IHAC), e Professor Permanente do Programa de Pós-Graduação em Cultura e Sociedade (Pós-Cultura), UFBA, Bahia, Brasil. E-mail: psleandro@gmail.com - https://orcid.org/0000-0003-1373-8007

${ }^{2}$ João Victor Iglesias. Graduando do Bacharelado Interdisciplinar em Humanidades da Universidade Federal da Bahia/UFBA, Brasil. jviglesias98@gmail.com - https://orcid.org/0000-0002-0354-0788
} 
presentation of the bill in 2017, until its approval in the first round, highlighting the antagonisms performed in the parliamentary scene. We examine ESP's connections with the "cultural Marxism" thesis and its transformation into a political asset in recent Brazil, by analyzing how conservative groups have set new ideas of fundamental rights subjects. The article is based on the methodological tools proposed by controversy analysis.

Keywords: Escola sem Partido; cultural marxism; cultural wars.

\section{"Meu filho, minhas regras": o caso do Escola sem Partido em Belo Horizonte}

\section{Introdução}

No início da década de 1980, a Universidade Stanford, uma das mais prestigiadas dos EUA, decidiu reelaborar os moldes de um curso que oferecia a todos os seus calouros, desde os anos 1930, sobre a história da civilização no Ocidente ${ }^{3}$. Foi assim que o Conselho Acadêmico aprovou a criação de uma nova disciplina obrigatória, baseada em um programa de leitura de 15 clássicos da filosofia e da literatura. O objetivo do curso, chamado "Cultura Ocidental", era situar os ingressantes em um mesmo solo epistemológico, apresentando uma introdução à tradição intelectual que seria comum a todos. Decorridos sete anos de sua implementação, contudo, uma marcha contra o curso mobilizou cerca de 500 estudantes e

\footnotetext{
${ }^{3}$ Ver:

https://web.stanford.edu/dept/news/stanfordtod ay/ed/9705/9705ncf1.html. Acesso em: 22 ago. 2020.
}

chegou a contar com a presença do reverendo Jesse Jackson, ícone da luta antirracista nos EUA. O grupo protestava contra a bibliografia da "Cultura Ocidental", que previa obras de pensadores como Platão, Homero, Lutero, Voltaire, Marx e Freud, mas não contemplava textos de mulheres, autores não-europeus ou contemporâneos. (PRATT, 1999)

Nas décadas anteriores, Stanford havia se tornado uma das instituições de ensino pioneiras em políticas de ação afirmativa nos EUA, tendo adotado medidas que pluralizaram o perfil social, étnico e racial de seu alunado e de seu próprio corpo docente ${ }^{4}$. Essa nova comunidade acadêmica engajou-se na

\footnotetext{
${ }^{4}$ Já nos anos 1970, jovens doutores e doutoras negros/as e latinos/as ingressaram no quadro docente da instituição, novidade que seria percebida com o surgimento de programas e centros de pesquisa dedicados a estudos feministas, africanos/afro-americanos e latinoamericanos. Ver: PRATT, 1999.
} 
crítica ao curso "Cultura Ocidental" e promoveu um extenso debate sobre a importância de serem diversificadas as referências intelectuais oferecidas aos calouros. $\mathrm{O}$ resultado do tensionamento foi o desenho de uma nova disciplina, chamada "Cultura, Ideias e Valores", baseada em uma bibliografia que preservava obras canônicas, mas incluía livros como "Me chamo Rigoberta Menchú e assim me nasceu a consciência", testemunho da ativista indígena guatemalteca Rigoberta Menchú.

O que poderia ser um debate interno à Universidade foi capaz de precipitar uma polêmica nacional. Grupos conservadores do país, representados por autoridades como o Secretário de Educação do governo de Ronald Reagan, William Bennett, abraçaram uma campanha contrária à proposta de Stanford, sob a acusação de que a mudança do currículo correspondia a uma ameaça aos marcos civilizatórios do Ocidente. A incorporação de leituras heterodoxas em um curso obrigatório, no contexto de uma universidade de ponta, levou acadêmicos e políticos conservadores do país a sentirem "a perda do monopólio como a perda do todo"
(PRATT, 1999, p. 183). Assim, embora a iniciativa tenha se consolidado em Stanford e influenciado outros campi nos anos seguintes, as escolhas e estratégias pedagógicas adotadas pelas instituições de ensino vieram a se tornar um candente tópico da agenda política dos EUA ao longo das últimas décadas.

Recuperamos este caso, ocorrido no fim dos anos 1980, buscando realçar as tramas entre os campos da cultura e da educação que se refletem no currículo e nas práticas das instituições de ensino. Utilizando o exemplo da Universidade Stanford, queremos introduzir a discussão de um fenômeno que não se restringe à cena norte-americana de décadas atrás, mas, pelo contrário, parece ter sinuosas repercussões na atualidade de nosso país.

A polêmica em torno do curso "Cultura Ocidental" é considerada um dos pontos-chave das guerras culturais nos EUA. Esse termo foi cunhado pelo sociólogo James Hunter (1991) com o intuito de descrever a cena de conflito instaurada na 
PAULA, Leandro de; IGLESIAS, João Victor. "Meu filho, minhas regras": o caso do Escola sem partido em Belo Horizonte. PragMATIZES - Revista Latino-Americana de Estudos em Cultura, Niterói/RJ, Ano 11, n. 20, p. 136-161, março 2021. sociedade norte-americana ao longo da década de 1980, em virtude de uma inflexão nos modos de percepção do antagonismo político. A tese central de Hunter poderia ser assim resumida: se as cisões políticas haviam sido historicamente sobredeterminadas por diferentes concepções da ordem econômica, a oposição entre direita e esquerda estaria se tornando crescentemente subordinada a disputas no campo da cultura.

Esse fenômeno decorria da consolidação das pautas emancipatórias trazidas à tona pelos movimentos civis dos anos 1970, mas também pela reação conservadora expressa por grupos como a Maioria Moral $^{5}$, que impulsionou a formação de uma bancada cristã no Congresso norte-americano. Tais acontecimentos acabaram por dar visibilidade aos dissensos sociais nos modos de compreensão da autoridade moral, bem como do papel do Estado diante da diversidade das formas de vida e de sua inscrição nos quadros sociais

\footnotetext{
${ }^{5}$ Fundada em 1979pelo pastor batista Jerry Falwell e encampada por poderosas correntes do Partido Republicano, a "Moral Majority" se organizava em comitês estaduais nos quais lideranças e leigos conservadores de diferentes denominações militavam em prol da "moralidade cristã", tida como representante da maioria dos cidadãos estadunidenses.
}

de reconhecimento. Assim, questões de natureza religiosa, étnica, racial, sexual e de gênero, dentre outras, passaram a protagonizar os debates que mobilizavam a nação $e$, por consequência, condicionavam as disputas eleitorais.

Se esse filtro analítico fez sentido para a cena norte-americana, diversos autores vêm apontando a pertinência da chave da guerra cultural também para a leitura da paisagem brasileira recente (NUNES, 2020; GALLEGO; ORTELLATO; MORETTO, 2014). Isso porque, já há ao menos meia década, o esgarçamento de nossa vida política vem se traduzindo no fenômeno que temos chamado genericamente de "polarização". A imagem de um país cindido em dois polos se difundiu como sugestão de certa experiência de acirramento dos antagonismos político-ideológicos, processo histórico que teve no impeachment de Dilma Rousseff seu momento catalisador e na ascensão de Jair Bolsonaro um explícito desdobramento.

Dado o perfil do atual Presidente da República e das pautas comportamentais que defende, sua vitória nas urnas parece exemplificar 
como o foco das lutas políticas tem sido modificado também no Brasil por meio das guerras culturais. Podemos considerar que as questões que dividem o país hoje dizem respeito especialmente à forma como a sociedade imagina a si própria no terreno dos valores morais e das crenças que Ihe seriam inegociáveis. É assim que, apelando a premissas nacionalistas e religiosas, o mote do projeto Bolsonaro - "Brasil acima de tudo, Deus acima de todos" - traduz um ideal de uniformidade sociopolítica que, para ser cumprido, demanda o permanente controle das diferenças e dos entendimentos do que são o país, sua história e sua sociedade.

Neste texto, queremos chamar atenção para os condicionantes culturais que atravessam essa cena política complexa, e para seus efeitos sobre o debate em torno da educação e do papel da escola. Propomos para o texto dois objetivos centrais. O primeiro consiste em apresentar uma breve genealogia do movimento Escola sem Partido (ESP), destacando seu vínculo com a tese do "marxismo cultural", sintomaticamente surgida em meio àquela atmosfera de dissenso instalada nos EUA das últimas décadas. O segundo intuito é observar a transformação do ESP em um ativo político no panorama brasileiro atual, ressaltando sua presença em diferentes instâncias legislativas e descrevendo o caso específico de sua aprovação, como projeto de lei, no município de Belo Horizonte.

Nosso esforço mira, portanto, o trajeto cumprido por uma convicção político-ideológica até sua institucionalização: acessamos o problema das guerras culturais observandocomo um discurso de traços conspiratóriose difusos originado na cena norte-americana veio a se afirmar como projeto de política públicaem uma grande capital brasileira. No percurso dessa abordagem, discutiremos elementos que cooperam para a disputa em torno do campo da educação hoje, desde as guinadas de atuação do espectro da direita até o ambiente político em torno do ESP em Belo Horizonte.

Para perseguir esses objetivos, dividimos o texto em duas seções principais. $\mathrm{Na}$ primeira, apresentaremos 0 ferramental metodológico que sustenta nossa investigação e algumas transições ocorridas no modelo de engajamento 
político do campo conservador nas últimas décadas, comentando o surgimento da tese do marxismo cultural nos EUA e sua divulgação no Brasil por ideólogos e formadores de opinião. $\mathrm{Na}$ segunda seção, descrevemos $\mathrm{o}$ fortalecimento da pauta legislativa do ESP e analisamos os embates parlamentares que rondaram sua apreciação em $\mathrm{BH}$. No fim, comentamos como os argumentos em torno do projeto mobilizam uma mesma linguagem jurídica, em benefício de diferentes concepções de sujeitos de direitos fundamentais.

\section{Marxismo cultural: história e} desdobramentos de uma tese

Com o objetivo de sondar a vocação beligerante presente na atualidade política brasileira, a metodologia aplicada na construção deste artigo esteve pautada na análise de controvérsias públicas, instrumento derivado da Teoria Ator-Rede de Bruno Latour e sistematizado por Tommaso Venturini (2009). Tal pressuposto metodológico aponta que, frente aos fenômenos a serem examinados, o protagonismo em geral exercido pelas premissas teóricas do pesquisador deve ser transferido para as racionalidades dos próprios atores envolvidos no processo de disputa. Noutros termos, mais do que nossos juízos como analistas, o que importa enquanto procedimento heurístico é a investigação das vozes implicadas no embate e dos meios empenhados em sua performance pública.

Um dos compromissos a que esse aporte nos constrange então é que não limitemos a interpretação de um fenômeno social complexo a apenas um referencial teórico, pelo qual seríamos capazes de descortinar lógicas inacessíveis aos atores em disputa. Ao contrário, a análise de controvérsias estipula que devemos levar a sério o que eles dizem, por mais contrastantes que seus valores e ideias pareçam a nosso próprio repertório político, cognitivo e moral. $\mathrm{Na}$ construção do objeto de estudo, essa metodologia nos exige admitir como legítimos todos os pontos de vista trazidos pelos atores do conflito, já que não desempenhamos o papel de juízes da disputa, mas de observadores das parcialidades que formam a controvérsia e de seus embates jurídicos, políticos, midiáticos etc. 
PAULA, Leandro de; IGLESIAS, João Victor. "Meu filho, minhas regras": o caso do Escola sem partido em Belo Horizonte. PragMATIZES - Revista Latino-Americana de Estudos em Cultura, Niterói/RJ, Ano 11, n. 20, p. 136-161, março 2021.

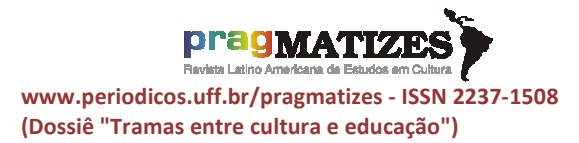

Quando perguntado sobre as regras para bem se cartografar tais situações de confronto, Bruno Latour resumiu: "apenas olhe para a controvérsia e diga o que vê" (VENTURINI, 2009, p. 799) ${ }^{6}$ A sugestão nada tem de trivial: ela orienta que devemos evitar que a análise assuma tons críticoprescritivos, a fim de que as racionalidades das diferentes partes de um litígio possam de fato vir à tona. Essa predisposição não significa, contudo, que advoguemos posição de neutralidade diante dos fenômenos. Antes, que suspendamos a urgência em classificar os pleitos em disputa pelos parâmetros que já portamos, optando, a contrapelo, por narrar a ação situada em sua máxima amplitude, à procura de suas ambiguidades.

Esse conjunto de princípios nos guiou na realização do presente estudo, levando-nos a um exame da batalha em torno do Escola sem Partido na Câmara dos Vereadores de Belo Horizonte, que chegou a saltar do campo dos debates ideológicos aos termos da agressão física entre

\footnotetext{
${ }^{6}$ No original: Just look at the controversies and tell what you see.
}

parlamentares, em um processo repleto de reviravoltas e manobras legislativas. Para descrever esse caso, significativo por se tratar da primeira capital brasileira a aprovar um projeto de lei nos moldes do ESP, perscrutamos um conjunto variado de fontes, como atas de sessões legislativas, pareceres de comissões parlamentares, materiais de imprensa, declarações de autoridades e documentos de órgãos oficiais de governo.

No processo de investigação, notamos que as disputas em torno do ESP eram fortemente influenciadas por aquilo que atores do espectro da direita vêm chamando de marxismo cultural, o que nos demandou uma revisão da literatura a respeito dessa tese. Para exemplificar sua pregnância no campo conservador hoje, lembramos que o plano de governo ${ }^{7}$ da candidatura de Jair Bolsonaro ao Planalto, submetido ao Tribunal Superior Eleitoral em 2018, afirmava que "nos últimos 30 anos o marxismo cultural e suas derivações como o

\footnotetext{
${ }^{7}$ Disponível em:

http://divulgacandcontas.tse.jus.br/candidatura s/oficial/2018/BR/BR/2022802018/2800006145 17/proposta_1534284632231.pdf. Acesso em: 20 ago. 2020.
} 
PAULA, Leandro de; IGLESIAS, João Victor. "Meu filho, minhas regras": o caso do Escola sem partido em Belo Horizonte. PragMATIZES - Revista Latino-Americana de Estudos em Cultura, Niterói/RJ, Ano 11, n. 20, p. 136-161, março 2021. gramscismo, se uniu às oligarquias corruptas para minar os valores da Nação e da família brasileira". O diagnóstico era seguido do compromisso do então candidato, grafado em caixa alta: "PRECISAMOS NOS LIBERTAR!VAMOS NOS LIBERTAR!".

Segundo Žižek (2018), a tese do marxismo cultural consistiria no ponto nevrálgico da coalizão que envolve as "novas direitas" surgidas após a década de 1990 nos EUA, e que, hoje, ganham considerável espaço na cena política de muitos países ao redor do mundo, dentre eles o Brasil. Assim, reconhecemos a importância de recuperar a genealogia dessa ideia, reconstituir sua chegada ao Brasil e descrever sua tradução em um projeto de política pública de expressivo impacto para o campo da educação.

Para fins terminológicos, vale definir, primeiramente, 0 que chamamos de "novas direitas". Ao analisar aemergência de grupos políticos que culminaram na eleição de Donald Trump nos EUA, Angela Nagle (2017) detecta que a crença na tese do marxismo cultural é um elementochave para a consolidação dessa nova militância. Já Camila Rocha (2018) aponta que, no Brasil recente, uma corrente de pensamento ultraliberal em termos econômicos e conservadora nos costumes articulou-se de forma quase silenciosa desde meados dos anos 2000. Esse perfil político, contudo, traria heranças da história nacional, já que, em meio à ditadura militar, liberais ortodoxos e conservadores morais compuseram uma aliança sólida com o intuito de combater o que entendiam ser uma ameaça comunista a rondar o Brasil. Esse pacto aos poucos foi perdendo sentido frente aos consensos que originaram a Constituição de 1988, daí decorrendo uma separação provisória entre as duas vertentes de pensamento.

Segundo Rocha, o arranjo social que modelou a Nova República foi responsável por tornar invisíveis no debate público os grupos que se identificavam com a antiga aliança ultraliberal-conservadora.

Imediatamente conectados às memórias repressivas do regime militar, esses grupos acabaram por se tornar uma espécie de "direita envergonhada", sem expressividade frente ao pêndulo que condicionou a 
PAULA, Leandro de; IGLESIAS, João Victor. "Meu filho, minhas regras": o caso do Escola sem partido em Belo Horizonte. PragMATIZES - Revista Latino-Americana de Estudos em Cultura, Niterói/RJ, Ano 11, n. 20, p. 136-161, março 2021. política brasileira a partir dos anos 1990 com a oposição entre o Partido da Social Democracia Brasileira (PSDB) e o Partido dos Trabalhadores (PT). Contudo, o caso do "mensalão" durante o primeiro mandato de Lula suscitou uma reativação dessa aliança, agora mobilizada contra as práticas e ideologias encampadas pelo Governo Federal da época. Somavase a esse contexto a disseminação no Brasil de plataformas de comunicação como fóruns e comunidades virtuais, que permitiram uma articulação horizontal desses anseios políticos e sua gradativa consolidação sob a forma de um movimento.

Tanto no Brasil quanto nos EUA, as novas direitas sinalizam um realinhamento do espectro político conservador, cuja batalha teria deixado de ser travada nos altos andares das corporações e gabinetes políticos, para se dirigir ao território que entendem ser dominado pela esquerda: o Estado Ampliado. Ideia cunhada por Gramsci, essa expressão indica que as lutas políticas não são disputadas apenas no interior dos aparelhos burocráticos do Estado, mas também no terreno da sociedade civil e no campo das mentalidades. Logo, instituições como igrejas, escolas, universidades, teatros e outras organizações que produzem e difundem ideias seriam parte fundamental de todo processo de transformação sociopolítica (BUCKEL; FISCHER-LESCANO, 2009). A partir desse entendimento, que entendem ser uma estratégia orquestrada pela esquerda na luta por hegemonia, as novas direitas passam a alargar seu campo de militância, buscando influenciar as políticas educacionais, os conteúdos midiáticos, os movimentos religiosos, dentre outras arenas de atuação.

A tese do marxismo cultural corresponde a um empreendimento teórico feito por think tanks ${ }^{8}$ atrelados a lobistas e políticos conservadores dos EUA da década de 1990, tendo sido a Convenção do Partido Republicano de 1992 um evento significativo para a difusão da tese (NAGLE, 2017). Na ocasião, Pat Buchannan, influente político

\footnotetext{
${ }^{8} \mathrm{~A}$ expressão em inglês "think tank" define o perfil de instituições que atuam na produção de pesquisas e no levantamento de dados com o intuito de influenciar o debate público e subsidiar governos e outras organizações na tarefa de elaboração e implementação de suas políticas.
} 
conservador, proferiu um discurso ${ }^{9}$ no qual afirmava que um possível governo Bill Clinton, candidato Democrata, representaria para o país um ciclo caracterizado por "aborto sob demanda", "direitos homossexuais", "discriminação de escolas religiosas" e "mulheres em guerra". A partir dessa época, ganhou maior circulação, no debate público norte-americano, a ideia de uma campanha oculta em prol da instauração de um regime comunista por meio do ataque ao que seriam os pilares da civilização ocidental, incluindo a religião judaicocristã e a família tradicional.

No Brasil, o principal vocalizador da tese do marxismo cultural foi Olavo de Carvalho, autor de grande influência no processo de ideologização das novas direitas locais. O debate sobre o tema pode ser encontrado em alguns de seus livros que se tornaram sucesso de venda, como "O mínimo que você precisa saber para não ser um idiota", obra presente na mesa de Jair Bolsonaro em seu primeiro discurso à

${ }^{9}$ Discurso disponível em: https://buchanan.org/blog/1992-republicannational-convention-speech-148. Acesso em: 23 ago. 2020. nação após eleito $^{10}$. Embora abordasse a ideia em seus cursos desde o fim dos anos $1980^{11}$, foi em um artigo publicado no jornal O Globo em 2002 que o autor introduziu a tese para a audiência brasileira mais ampla.

Segundo Carvalho (2002), os teóricos marxistas teriam abandonado suas convicções acerca da necessidade de uma revolução armada após constatarem que, durante a Primeira Guerra, o proletariado lutara em defesa do Estado burguês, mesmo sendo ciente de suas opressões. Esses intelectuais teriam então avançado um conceito de batalha silenciosa, direcionada à conquista das mentes dos cidadãos, por meio do controle das organizações sociais difusoras do conhecimento. Para o autor, a Escola de Frankfurt ${ }^{12}$

\footnotetext{
${ }^{10}$ Disponível em:

https://f5.folha.uol.com.br/colunistas/bibliotecada-vivi/2018/11/conheca-o-livro-que-foimostrado-por-bolsonaro-no-discurso-apos-sereleito-presidente.shtml. Acesso em: 15 jul. 2020.

${ }^{11}$ Ver: https://olavodecarvalho.org/a-nova-erae-a-revolucao-cultural-capitulo-ii/. Acesso em: 22 ago. 2020.

${ }^{12}$ Sediada na Universidade de Frankfurt e impulsionada a partir dos anos 1920, essa "Escola" consistiu na reunião de diversos intelectuais com o objetivo de reler a tradição do marxismo e propor novos parâmetros de análise social, dentre os quais se destacam Theodor Adorno, Max Horkheimer, Herbert Marcuse e Jürgen Habermas.
} 
PAULA, Leandro de; IGLESIAS, João Victor. "Meu filho, minhas regras": o caso do Escola sem partido em Belo Horizonte. PragMATIZES - Revista Latino-Americana de Estudos em Cultura, Niterói/RJ, Ano 11, n. 20, p. 136-161, março 2021. teria sido um think tank que, abandonando a ilusão de um levante universal dos proletários, passara a dedicar-se ao único empreendimento viável que restaria, "destruir a cultura ocidental".

Os homens de Frankfurt,
especialmente Horkheimer, Adorno e
Marcuse, tiveram a idéia de misturar
Freud e Marx, concluindo que a
cultura ocidental era uma doença,
que todo mundo educado nela sofria
de "personalidade autoritária", que a
população ocidental deveria ser
reduzida à condição de paciente de
hospício e submetida a uma
"psicoterapia coletiva". Estava
portanto inaugurada, depois do
marxismo clássico, do marxismo
soviético e do marxismo revisionista
de Eduard Bernstein (o primeiro
tucano), a quarta modalidade de
marxismo: o marxismo cultural.
(CARVALHO, 2002)

Nos anos subsequentes ao artigo de Carvalho, houve, sobretudo durante o segundo mandato de Lula, um crescimento orgânico das novas direitas brasileiras. Como mostra Rocha (2018), esses grupos em ascensão, articulados em comunidades digitais, difundiam ideias que, naquele momento, ainda não encontravam tanto espaço no debate público brasileiro.Movimentos como o "Endireita Brasil", compostos por jovens estudantes, advogados e empresários - como o atual Ministro do Meio Ambiente Ricardo Salles -, foram se tornando cada vez mais comuns e cooperando para a assimilação da tese do marxismo cultural no país. Um exemplo desse processo é um vídeo divulgado na página desse grupo no Facebook $^{13}$, no qual o padre Paulo Ricardo, líder religioso conhecido por suas posições reacionárias, afirma que as escolas brasileiras estariam empenhadas na tarefa da "lenta e gradual imbecilização" dos alunos, para que se tornassem presas fáceis das ideias marxistas. Como sabemos, a crise política desdobrada no governo de Dilma Rousseff impulsionou a disseminação de ideias afins sob a forma do antipetismo, pulsão social corresponsável pela difusão da tese do marxismo cultural e da proposta do ESP no país, conforme abordaremos na seção seguinte.

\section{Escola Sem Partido: contexto e discussão em Belo Horizonte \\ Esboçadas a tese do marxismo} cultural e sua trajetória dos EUA dos anos 1990 à cena brasileira da última

\footnotetext{
${ }^{13} \mathrm{Em}$ sua página do Facebook, o movimento Endireita Brasil compartilhou, por exemplo, uma palestra do padre Paulo Ricardo, sustentando que em: https://www.facebook.com/endireitabrasil/video s/10154247999097344. Acesso em: 15 jul. 2020.
} 
PAULA, Leandro de; IGLESIAS, João Victor. "Meu filho, minhas regras": o caso do Escola sem partido em Belo Horizonte. PragMATIZES - Revista Latino-Americana de Estudos em Cultura, Niterói/RJ, Ano 11, n. 20, p. 136-161, março 2021.

década, buscamos agora compreender um de seus efeitos em nossa atualidade histórica analisando o caso do ESP. O movimento surgiu no ano de 2003, na cidade de São Paulo, quando o advogado e procurador do Estado Miguel Nagib se revoltou ao saber que um professor da escola de sua filha havia comparado São Francisco de Assis ao líder revolucionário Che Guevara (BEDINELLI, 2016). A partir desse fato, Nagib decidiu realizar uma campanha, dentro da própria escola, em defesa de uma "desideologização" das salas de aula. Inconformado coma baixa repercussão da iniciativa, o advogado resolveu criar um site que visava a receber denúncias, por parte de alunos e pais, acerca de um possível monopólio do discurso de esquerda nas escolas.

Seguindo a trilha de Moura (2016), podemos identificar a existência de três grandes divisores de águas para que o ESP tenha se tornado pauta no panorama político do Brasil. O primeiro aconteceu em 2007, com um artigo assinado por Ali Kamel, um dos principais nomes do jornalismo das Organizações Globo, publicado no jornal impresso do grupo ${ }^{14}$. Kamel criticava o conteúdo da coleção "Nova História Crítica - $8^{\mathrm{a}}$ série, distribuída gratuitamente pelo MEC a $750 \mathrm{mil}$ alunos da rede pública" (KAMEL, 2007), afirmando que os livros não passariam de "uma tentativa de fazer nossas crianças acreditarem que o capitalismo é mau e que a solução de todos os problemas é o socialismo, que só fracassou até aqui por culpa de burocratas autoritários".

O movimento deNagib, que se dirigia a questões afins, acabou ganhando repercussão nas mídias à época, como demonstra, por exemplo, um texto do jornalista Reinaldo Azevedode 2008, intitulado "Por uma Escola sem Partido" (AZEVEDO, 2008). O artigo fazia menção direta ao texto de Kamel e ressaltava a importância de uma escola livre da manipulação de informações em prol do Partido dos Trabalhadores, chamando a atenção dos pais para o tema, "como fazem aqueles que hoje colaboram com o site Escola Sem Partido". Esses textos de dois importantes agentes da imprensa

\footnotetext{
${ }^{14}$ Disponível em:

http://www.alikamel.com.br/artigos/queensinam-nossas-criancas.php. Acesso em: 15 jul. 2020.
} 
PAULA, Leandro de; IGLESIAS, João Victor. "Meu filho, minhas regras": o caso do Escola sem partido em Belo Horizonte. PragMATIZES - Revista Latino-Americana de Estudos em Cultura, Niterói/RJ, Ano 11, n. 20, p. 136-161, março 2021. levaram a públicos mais amplos a narrativa de uma ideologização/doutrinação da esquerda nas salas de aula brasileiras.

O segundo momento crucial para o ESP aconteceu em 2011, após o Ministério da Educação anunciar o Programa Brasil sem Homofobia, conjunto de materiais didáticos para combater a discriminação contra pessoas LGBTs, que foi apelidado pelo então deputado Jair Bolsonaro de "kit gay" (LEITE, 2019). O ESP ganhou notoriedade ao criticar o conteúdo dos materiais, por sua suposta tentativa de influenciar um campo da formação que caberia apenas à família. Marcava presença ali, pela primeira vez, o discurso contrário à "ideologia de gênero", o que correspondia a uma importante guinada do movimento: se, antes, sua pauta estava vinculada a uma perspectiva político-ideológica, agora a agenda se tornara moral, assumindo maior apelo junto a diferentes camadas da população. (MIGUEL, 2016)

O terceiro momento importante para o movimento teria sido o período de radicalização política ocorrido nas eleições de 2014, quando os apoiadores do candidato Aécio Neves acusaram o governo Dilma de estimular uma doutrinação "comunistahomossexual" nas escolas do Brasil, reproduzindo forma e conteúdo denuncistas que caracterizaram as eleições presidenciais nos EUA de $1992^{15}$. Nesse contexto políticohistórico, o então Deputado Estadual (RJ) Flavio Bolsonaro convidou Miguel Nagib a redigir um projeto de lei, batizado pelo próprio filho do Presidente da República de "Lei do Escola sem Partido", que visava a positivar a proteção às crenças morais dos estudantes frente ao perigo da doutrinação (MOURA, 2016). Após a proposta ser encaminhada à Assembleia Estadual do Rio de Janeiro, Carlos Bolsonaro, vereador da cidade do Rio de Janeiro, também submeteu a pauta para votação na Câmara Municipal, assim como ocorreu em outros estados e municípios, além do Senado Federal.

Essas repercussões fizeram o movimento iniciado por Nagib, um assumido entusiasta das ideias de

\footnotetext{
${ }^{15}$ Conforme comentamos anteriormente, essa foi a campanha na qual a tese do marxismo cultural despontou com mais evidência, por meio da atuação de Pat Buchannan e outros agentes do Partido Republicano.
} 
PAULA, Leandro de; IGLESIAS, João Victor. "Meu filho, minhas regras": o caso do Escola sem partido em Belo Horizonte. PragMATIZES - Revista Latino-Americana de Estudos em Cultura, Niterói/RJ, Ano 11, n. 20, p. 136-161, março 2021.
Olavo de Carvalho $^{16}$, tornar-se instrumento central da guerra declarada pelas novas direitas brasileiras ao "marxismo cultural". Ao se transformar em projeto de política pública e ganhar linguagem jurídica, prescrevendo ações e deveres, o ESP exemplifica como aquela tese, gerada por think tanks dos EUA e importada para o Brasil nas produções de Carvalho, têm produzido efeitos concretos na realidade recente.

Antes de iniciarmos a análise do caso de Belo Horizonte, ressaltamos os desdobramentos das propostas submetidas ao Senado Federal e à Assembleia Legislativa de Alagoas, ambas em 2016. Na Câmara Alta, o projeto $^{17}$ de autoria do Senador Magno Malta foi apresentado, mas o Presidente da Comissão de Educação, Cultura e Esporte do Senado à época, Cristovam Buarque, emitiu parecer contrário, alegando sua

\footnotetext{
${ }^{16}$ Ver:

https://www.metropoles.com/brasil/politicabrasil/nao-quero-pregacao-anticomunista-diznagib-do-escola-sem-partido. Acesso em: 25 ago. 2020.

${ }^{17}$ Disponível em: https://www25.senado.leg.br/web/atividade/ma terias/-/materia/125666. Acesso em: 15 jul. 2020.
}

inconstitucionalidade $^{18}$. Já no Estado de Alagoas, o projeto intitulado "Escola Livre" chegou a ser aprovado, porém jamais entrou em vigor, já foi vetado pelo governador Renan Calheiros Filho. A Câmara, então, optou por derrubar o impedimento, medida que exigiu voto favorável da maioria absoluta dos parlamentares $\mathrm{e}$ demonstrou a importância do projeto para os deputados e a força eleitoral da pauta ${ }^{19}$. Logo depois, o Ministro da Educação Aloizio Mercadante protocolou uma Ação Direta de Inconstitucionalidade (ADIN), analisada no Supremo Tribunal Federal pelo Ministro Luiz Roberto Barroso, que entendeu que os preceitos do projeto já eram previstos pela Constituição, e que, mais do que estimular o pluralismo ideológico, a proposta vedaria certas opiniões e correntes de pensamento, não se

\footnotetext{
${ }^{18}$ Disponível em: https://legis.senado.leg.br/sdleggetter/documento?dm=7268020\&ts $=15939301$ $78001 \&$ disposition=inline. Acesso em: 15 jul. 2020.

${ }^{19}$ Disponível em:

http://g1.globo.com/al/alagoas/noticia/2016/04/ deputados-de-alagoas-decidem-derrubar-vetoao-projeto-escola-livre.html. Acesso em: 15 jul. 2020.
} 
PAULA, Leandro de; IGLESIAS, João Victor. "Meu filho, minhas regras": o caso do Escola sem partido em Belo Horizonte. PragMATIZES - Revista Latino-Americana de Estudos em Cultura, Niterói/RJ, Ano 11, n. 20, p. 136-161, março 2021. coadunando com os pilares da democracia ${ }^{20}$.

$\mathrm{Na}$ esteira dessas iniciativas anteriores, o projeto da "Lei da Escola Sem Partido" foi submetido à Câmara Municipal de Belo Horizonte em junho de 2017. Cabe assinalar que, no plano das inclinações político-eleitorais, a rejeição à agenda do PT começou a se notabilizar na capital mineira já em 2010, quando Dilma Rousseff recebeu menos votos do que José Serra ${ }^{21}$. Nos pleitos seguintes, o percentual de votos recebidos pelo partido só fez diminuir $^{22}$, e em 2018 Bolsonaro recebeu em $\mathrm{BH} 65 \%$ dos votos válidos, contra $34 \%$ para Fernando Haddad $^{23}$. Se podemos inferir algo desses breves dados, diríamos que os

\footnotetext{
${ }^{20}$ Disponível em:

https://www.conjur.com.br/2017-mar22/liminar-suspende-lei-alagoas-criouprograma-escola-livre. Acesso em: 15 jul. 2020.

${ }^{21}$ Disponível em:

http://g1.globo.com/especiais/eleicoes2010/noticia/2010/11/veja-votacao-de-dilma-eserra-nas-cidades-com-mais-de-200-mileleitores.html. Acesso em: 30 ago. 2020.

${ }^{22}$ Ver:

https://www.em.com.br/app/noticia/politica/201 4/10/27/interna_politica,584070/aecio-venceuem-bh-e-na-maioria-dos-municipios-da-regiaometropolitana.shtml. Acesso em: 30 ago. 2020.

${ }^{23}$ Ver:

https://www.em.com.br/app/noticia/politica/201 8/10/28/interna_politica,1000942/em-belohorizonte-bolsonaro-teve-65-6-dos-votosvalidos-e-haddad-34.shtml. Acesso em: 30 ago. 2020.
}

humores políticos na cidade acompanharam a deriva nacional do antipetismo e da negação da política tradicional, ideia que pode ser reforçada quando lembramos da vitória, em 2016, do prefeito Alexandre Kalil (PHS). Em sua primeira candidatura a um cargo público, o exdirigente do Atlético Mineiro, conhecido pelo temperamento falastrão e polêmico, derrotou João Leite, que contava com a máquina do PSDB e o apoio de Aécio Neves.

Em meio a esse contexto político, a apreciação do ESP na capital mineira envolveu a sociedade civil e a classe política em uma controvérsia em torno das noções de "ideologia de gênero" e de "doutrinação em sala de aula". No texto do projeto de $l \mathrm{e}^{24}$, duas concepções de direitos fundamentais se colocavam como rivais: a liberdade de ensinar do docente, contraposta à liberdade de consciência e de crença do estudante, ou seja, o direito de "que o seu conhecimento da realidade não seja manipulado, para fins políticos e ideológicos, pela ação dos

\footnotetext{
${ }^{24}$ Ver:http://cmbhsildownload.cmbh.mg.gov.br/ silinternet/servico/download/documentoVincula do?idDocumento=2c907f765c8e8a2d015cc59 a860d1711 .Acesso em: 30 ago. 2020.
} 
PAULA, Leandro de; IGLESIAS, João Victor. "Meu filho, minhas regras": o caso do Escola sem partido em Belo Horizonte. PragMATIZES - Revista Latino-Americana de Estudos em Cultura, Niterói/RJ, Ano 11, n. 20, p. 136-161, março 2021. professores". Isso porque seria "fato notório que professores e autores de livros didáticos" vinham utilizando suas aulas e obras para fazer com que os alunos "adotem padrões de julgamento e de conduta moral - especialmente moral sexual - incompatíveis com os que thes são ensinados por seus pais ou responsáveis".

A autoria do projeto de lei foi dividida por 21 vereadores de 9 diferentes partidos, fato que denota a singularidade do caso mineiro, já que, tradicionalmente, projetos de lei possuem apenas um proponente. De imediato, fica nítida a força da pauta e a sua capacidade de congregar políticos de diversos perfis, tornandose uma espécie de consenso suprapartidário em Belo Horizonte. A Câmara Municipal possui ali 41 assentos, e apenas os 21 signatários do programa já garantiriam quórum para aprová-lo.

No entanto, o que se viu nos trâmites relacionados à sua votação, ou seja, a passagem pelas Comissões Parlamentares pertinentes a seu mérito $^{25}$, foi uma sequência de

\footnotetext{
${ }^{25}$ Nesse sentido, vale observar o Título $X$ do regimento interno da Câmara Municipal de Belo Horizonte, que versa acerca do funcionamento das comissões e de como
}

reviravoltas em razão de mecanismos de obstrução realizados pela oposição. Isso contribuiu para o adiamento da votação e o aquecimento da controvérsia, coma mobilização de novos atores ao redor do debate. Analisaremos a seguir o percurso do projeto de lei pelas Comissões de: 1 . Legalidade e Justiça; 2. Educação, Ciência, Tecnologia, Cultura, Desporto, Lazer e Turismo; 3. Direitos Humanos e Defesa do Consumidor; e, por fim, 4. Administração Pública, até que fosse encaminhado para votação em primeiro turno. Veremos que, durante o processo que se estendeu de junho de 2017 a outubro de 2019, os ânimos em torno da matéria foram se acirrando e configurando uma inflamada disputa.

Após a apresentação do projeto, sua primeira análise foi de responsabilidade da Comissão de Legalidade e Justiça, sendo o relator designado para a tarefa o teólogo e advogado Irlan Melo (PSD), eleito vereador pela primeira vez em 2016. Em seu parecer, Melo enfatizou que o

funcionam os critérios para a escolha das comissões de acordo com a natureza do projeto de lei. Disponível em:

https://leismunicipais.com.br/regimentointerno-belo-horizonte-mg. Acesso em: 15 jul. 2020. 
projeto teria amparo constitucional e estaria respaldado por forte demanda popular, sob a justificativa da "descontaminação e desmonopolização política e ideológica das escolas" ${ }^{26}$. Para que se fizesse valer o preceito constitucional do pluralismo na questão da educação, o relator recomendava a transformação do projeto em lei.

A próxima apreciação se deu por parte da Comissão de Educação, Ciência, Tecnologia, Cultura, Desporto, Lazer e Turismo, que, tradicionalmente na Câmara dos Vereadores de Belo Horizonte, fica sob o comando de partidos à esquerda. Foi a partir desse momento que 0 ambiente em torno da proposta passou a ganhar nuances tensas, já que a ala de esquerda da Câmara manejou diversos recursos previstos pelo regulamento para postergar a sua apreciação, fazendo também com queprofessores vinculados a sindicatos e movimentos coletivistas passassem a acompanhar a questão de forma mais próxima.

\footnotetext{
${ }^{26}$ Ver:

http://cmbhsildownload.cmbh.mg.gov.br/silinter net/servico/download/documentoVinculado?id Documento $=2 \mathrm{c} 907 \mathrm{f} 765 \mathrm{~d} 425300015 \mathrm{~d} 570 \mathrm{a} 18 \mathrm{a}$ d095b. Acesso em: 30 ago. 2020.
}

O nome indicado pela Comissão para realizar a relatoria foi do vereador Professor Wendel Mesquita, do partido Solidariedade. Conforme o regulamento da Câmara, caso o relator designado não apresente o parecer no prazo de 30 dias, o presidente da Comissão pode solicitar a outro parlamentar que o faça. $E$ assim ocorreu: após decorrido o prazo sem apresentação do parecer, Gilson Reis, vereador pelo $\mathrm{PCdoB}$, foi nomeado como o novo responsável pela tarefa em agosto de 2017. Eis que tomou forma outra manobra por parte da oposição: ao solicitar um pedido de diligência $^{27}$ para a Secretaria de Educação do Município, o relator conseguiu adiar em 60 dias o prazo para a apreciação da proposta. Em outubro de 2017, Gilson Reis, professor de biologia e ex-presidente do Sindicato de Professores de Minas Gerais, apresentou relatoria expressamente contrária ao projeto, que chamou de "lei da mordaça" 28 .

\footnotetext{
${ }^{27}$ Ver:

http://cmbhsildownload.cmbh.mg.gov.br/silinter net/servico/download/documentoVinculado?id Documento=2c907f765dd2bd0a015df5296222 1022. Acesso em 2 set. 2020.

${ }^{28}$ Ver:

http://cmbhsildownload.cmbh.mg.gov.br/silinter net/servico/download/documentoVinculado?id
} 
PAULA, Leandro de; IGLESIAS, João Victor. "Meu filho, minhas regras": o caso do Escola sem partido em Belo Horizonte. PragMATIZES - Revista Latino-Americana de Estudos em Cultura, Niterói/RJ, Ano 11, n. 20, p. 136-161, março 2021.
Nesse ínterim, o Ministério Público Federal (MPF) encaminhou ofícios à Câmara Municipal de Belo Horizonte e aos presidentes das comissões responsáveis pela apreciação do projeto, reforçandoa inconstitucionalidade da legislações nos moldes do ESP, conforme posicionamento prévio do Supremo Tribunal Federal ${ }^{29}$. Contudo, mesmo sob o alerta e a rejeição de uma das Comissões, o projeto rumou para nova análise, dessa vez na Comissão de Direitos Humanos e Defesa do Consumidor, sendo encarregado da relatoria o vereador Mateus Simões, do Partido Novo. O parlamentar deu parecer ${ }^{30}$ favorável ao projeto, massugeriu emendas em alguns artigos, que acarretaram na rejeição de sua relatoria pela Comissão. Em seu lugar, foi designada a vereadora Áurea Carolina, do PSOL, cujo parecer vetou a proposta, sob o argumento de que os estudantes deveriam receber

Documento=2c907f765ecd6939015ef2f558d61 bd0. Acesso em: 2 set. 2020.

${ }^{29}$ Ver: https://veja.abril.com.br/politica/mpf-diza-camara-de-bh-que-escola-sem-partido-einconstitucional/. Acesso em: 2 set. 2020.

${ }^{30}$ Ver:

http://cmbhsildownload.cmbh.mg.gov.br/silinter net/servico/download/documentoVinculado?id Documento=2c907f765f0848d8015f5474deaa 2f1b. Acesso em: 2 set. 2020. "uma educação plena, plural e democrática, não podendo estar restrita às convicções de seus familiares"31.

Por fim, na Comissão de Administração Pública, a relatoria ficou sob encargo de Pedro Bueno, então membro do Podemos, que recorreu ao artifício da apresentação de diligências para adiar o prazo de apresentação da relatoria. O projeto deixou essa Comissão em fevereiro de 2018 sem ter seu parecer apreciado, retornando à Presidência da Câmara, para votação em primeiro turno. A fase inicial da controvérsia na capital mineira representou assim um embateinterno à Câmara, envolvendo representantes políticos e manobras institucionais.

O projeto de lei só retornaria à pauta para votação em setembro de 2019, após o período das eleições majoritárias no país. Uma bancada progressista na casa congregou os parlamentares Bella Gonçalves (suplente da Deputada Federal eleita Áurea Carolina) e Cida Falabella, do

\footnotetext{
${ }^{31}$ Ver:

http://cmbhsildownload.cmbh.mg.gov.br/silinter net/servico/download/documentoVinculado?id Documento=2c907f765f786e7f015f9cb0eb181 062. Acesso em: 2 set. 2020.
} 
PAULA, Leandro de; IGLESIAS, João Victor. "Meu filho, minhas regras": o caso do Escola sem partido em Belo Horizonte. PragMATIZES - Revista Latino-Americana de Estudos em Cultura, Niterói/RJ, Ano 11, n. 20, p. 136-161, março 2021. www.periodicos.uff.br/pragmatizes - ISSN 2237-1508 (Dossiê "Tramas entre cultura e educação")
PSOL; Pedro Patrus e Arnaldo Godoy, do PT; Gilson Reis, do PCdoB; e Pedro Bueno, eleito pelo PTN, à época da votação no Podemos. Tais vereadores compuseram uma frente de oposição, empenhada no que definiram como "processo de obstrução democrática ao projeto Escola Sem Partido"32, ensejado por requerimentose outros recursos que adiaram a votação por 13 dias. $^{33}$

Nas sessões ocorridas nesse período, foram registrados gritos, xingamentos e tumultos, com os assentos destinados a membros da sociedade civil totalmente preenchidos por professores, estudantes, membros de sindicatos e instituições relacionadas à educação, além de apoiadores do $\mathrm{ESP}^{34}$. O estopim do conflito deu-se em 9 de outubro daquele ano, quando, nas galerias, os opositores do projeto se

\footnotetext{
${ }^{32}$ Ver:

https://www.hojeemdia.com.br/horizontes/deba te-sobre-o-projeto-escola-sem-partido-geraconfusão-na-câmara-de-bh-veja-ov\%C3\%ADdeo-1.748418. Acesso em: 2 set. 2020.

${ }^{33}$ Ver:

https://www.em.com.br/app/noticia/politica/201 9/10/14/interna_politica,1092707/escola-sempartido-bh-e-a-primeira-capital-a-aprovarprojeto-na-camar.shtml. Acesso em: 2 set. 2020.

${ }^{34}$ Idem à nota anterior.
}

desentenderam com os seguranças da Câmara, logo após o vereador Gilson Reis ser ofendido por manifestantes apoiadores da proposta $^{35}$. A Guarda Municipal foi convocada para auxiliar os seguranças, e um docente membro do Sindicato dos Professores da Rede Municipal de Belo Horizonte (SindRede) foi acometido por um golpe, ficando desacordado ${ }^{36}$. Comentando o caso na sessão do dia seguinte, a vereadora Cida Falabella reverberou o sentido apaixonado da controvérsia: "o Escola com Mordaça é um projeto que nos fere de morte, e por isso estamos dando a vida por ele"37.

Por recomendação do departamento de segurança da Câmara, a vereadora Nelly Aquino, presidente da Casa, ordenou que todos os civis da galeria fossem retirados para que se desse sequência

\footnotetext{
${ }^{35}$ Disponível em: https://g1.globo.com/mg/minasgerais/noticia/2019/10/09/votacao-do-escolasem-partido-tem-confusao-na-camara-debh.ghtml. Acesso em: 15 jul. 2020.

${ }^{36}$ Disponível em:

https://www.facebook.com/gilsonreis65/photos/ a.528915523807421/2662577833774502/?typ e=3\&theater. Acesso em: 15 jul. 2020.

${ }^{37}$ Disponível em:

https://www.brasildefatomg.com.br/2019/10/10/ votacao-do-escola-sem-partido-provocaagressoes-na-camara-de-vereadores-de-bh. Acesso em: 15 jul. 2020.
} 
PAULA, Leandro de; IGLESIAS, João Victor. "Meu filho, minhas regras": o caso do Escola sem partido em Belo Horizonte. PragMATIZES - Revista Latino-Americana de Estudos em Cultura, Niterói/RJ, Ano 11, n. 20, p. 136-161, março 2021. à votação ${ }^{38}$. Em seu site, o SindRede definiu a atitude nos seguintes termos: "presidente da Câmara manda bater em professores para aprovar Escola com Mordaça"39. A sessão foi retomada com portões fechados e o acirramento do clima de antagonismo: vereadores contrários ao projeto ressaltavam o gesto antidemocrático da presidente da Câmara, que simbolicamente excluíra a presença do povo do processo decisório. Enquanto isso, os parlamentares favoráveis ao projeto bradavam contra os recursos utilizados pelos oponentes para dilatar o prazo para início da votação, já que as manobras impediam que outros projetos entrassem na pauta até que todos os órgãos se posicionassem quanto à matéria. ${ }^{40}$

$\mathrm{Na}$ fila para subir à tribuna $\mathrm{e}$ arguir um dos requerimentos

\footnotetext{
${ }^{38}$ Disponível em:

https://www.hojeemdia.com.br/horizontes/deba te-sobre-o-projeto-escola-sem-partido-geraconfus $\%$ C3\%A3o-na-c\%C3\%A2mara-de-bhveja-o-v\%C3\%ADdeo-1.748418. Acesso em: 15 jul. 2020.

${ }^{39}$ Disponível em: http://redebh.com.br/nelymanda-bater-em-professor/. Acesso em: 15 jul. 2020.

${ }^{40}$ Disponível em:

https://www.hojeemdia.com.br/primeiroplano/pauta-congelada-escola-sem-partidoimpede-tramita\%C3\%A7\%C3\%A3o-depropostas-no-legislativo-de-bh-1.748713. Acesso em: 6 set. 2020.
}

apresentados, os vereadores Bella Gonçalves, do PSOL, e Mateus Simões, do Partido Novo, digladiaram pela posse do microfone do plenário; Gilson Reis interveio na confusão e travou com Mateus Simões uma troca de empurrões ${ }^{41}$. Após mais dois adiamentos, finalmente a votação ocorreu no dia 11 de outubro de 2019: com 33 parlamentares presentes, o placar foi de 25 votos a favor do projeto e 8 contrários $^{42}$. O SindRede organizou, para a data, uma paralisação de professores da rede municipal de ensino, alegando que $80 \%$ das escolas de Belo Horizonte haviam suspendido as aulas. Por outro lado, a Secretaria Municipal de Educação afirmou que $94 \%$ das escolas estavam funcionando normalmente ${ }^{43}$. Foram registrados protestos de importantes instituições

\footnotetext{
${ }^{41}$ Disponível em:

https://www.em.com.br/app/noticia/gerais/2019 /10/10/interna_gerais, 1091825/mateussimoes-pede-desculpas-mas-gilson-reispretende-acionar-justica.shtml. Acesso em: 6 set. 2020.

${ }^{42}$ Ver:

http://cmbhsildownload.cmbh.mg.gov.br/silinter net/servico/download/documentoVinculado?id Documento=2c907f766d980c0c016dcc86eb11 232a. Acesso em: 15 jul. 2020.

${ }^{43}$ Disponível em:

https://www.otempo.com.br/politica/professore s-protestam-contra-escola-sem-partido-efechamento-de-galeria-1.2248020. Acesso em: 15 jul. 2020.
} 
PAULA, Leandro de; IGLESIAS, João Victor. "Meu filho, minhas regras": o caso do Escola sem partido em Belo Horizonte. PragMATIZES - Revista Latino-Americana de Estudos em Cultura, Niterói/RJ, Ano 11, n. 20, p. 136-161, março 2021. de ensino da capital mineira, e, na porta da Câmara Municipal, manifestações da União Nacional dos Estudantes, da Central Sindical e Popular, do Movimento por uma Universidade Popular e do Coletivo Para Todos ${ }^{44}$.

Tendo sido aprovado apenas em primeiro turno, o projeto "Lei do Escola Sem Partido" permanece na pauta da Câmara, onde voltará a passar por comissões temáticas que apreciarão emendas à proposta, antes que volte a plenário para votação final. Se aprovado, o projeto deverá ser encaminhado à sanção do prefeito da cidade. Alexandre Kalil, cujo primeiro mandato à frente de Belo Horizonte termina em 2020, já se mostrou crítico dos vereadores que apoiam a proposta, classificando o projeto de lei como "estúpido e idiota". ${ }^{45}$

No momento em que elaboramos este artigo, a controvérsia em torno do Escola Sem Partido em

\footnotetext{
${ }^{44}$ Disponível em:

https://www.em.com.br/app/noticia/90anos/201 8/10/18/interna 90 anos,998196/conheca-asescolas-publicas-que-contam-a-historia-debelo-horizonte.shtml. Acesso em: 15 jul. 2020.

${ }^{45}$ Ver:

https://educacao.uol.com.br/noticias/2019/10/1 4/vereadores-aprovam-em-1-turno-escolasem-partido-em-bh.htm. Acesso em: 5 set. 2020.
}

Belo Horizonte parece ainda longe de um desfecho, sendo capaz de engajar novos atores em torno de si, com visões contrastantes. O objetivo em descrever uma parte dessa disputa não é, obviamente, delimitar seu sentido histórico final, mas observar como o conflito tem configurado diferentes partes e antagonismos, fazendo com que os argumentos em pauta mobilizem afetos, protestos, medidas jurídicas e capitais políticos.

Em abril de 2020, ao julgar de forma colegiada uma ADIN acerca de um projeto de lei semelhante, aprovado no município de Nova Gama (GO) em 2015, o STF voltou a determinar que apenas a União teria competência para editar leis atinentes ao currículo escolar no $\mathrm{Brasil}^{46}$. A medida foi um golpe ao movimento Escola Sem Partido, cujos perfis oficiais se pronunciaram com um alerta sobre o risco que a decisão do STF representava à classe docente do país:

Ao declarar a inconstitucionalidade de leis q proíbem ideologia de gênero no ensino fundamental, STF pode acabar levando pais a fazer justiça c/as próprias mãos p/defender

\footnotetext{
${ }^{46}$ Disponível em:

http://www.stf.jus.br/arquivo/cms/noticiaNoticia Stf/anexo/ADPF457.pdf. Acesso em: 15 jul. 2020.
} 
PAULA, Leandro de; IGLESIAS, João Victor. "Meu filho, minhas regras": o caso do Escola sem partido em Belo Horizonte. PragMATIZES - Revisto Latino-Americana de Estudos em Cultura, Niterói/RJ, Ano 11, n. 20, p. 136-161, março 2021. a integridade psíquica e moral dos seus filhos e o direito sagrado de educá-los. Professores que se cuidem. $^{47}$

\section{Considerações Finais}

Entendemos que, independentemente do encaminhamento formal que o projeto do ESP venha a tomar em Belo Horizonte, a mera aprovação da proposta em primeiro turno é significativa pelos ânimos e interesses que revela. Como buscamos demonstrar, a eficácia da tese do marxismo cultural e sua conveniência enquanto plataforma política podem ser verificadas pela repercussão legislativa do ESP no Brasil, pauta que, mesmo após o encerramento do ciclo do PT no Governo Federal, parece seguir produzindo diferentes rendimentos políticos.

A despeito dessa popularidade, interessa destacar que a proposta do ESP não é consensual sequer entre as novas direitas. O próprio Olavo de Carvalho já se manifestou contrário à urgência que caracteriza o movimento na atualidade brasileira, uma vez que Ihe faltariam subsídios concretos para

\footnotetext{
${ }^{47}$ Disponível em:

https://twitter.com/escolasempartid/status/1254 168786699255812. Acesso em: 15 jul. 2020.
}

positivar em lei as medidas de proteção à suposta doutrinação da esquerda nas escolas. Em entrevista de 2018, o escritor afirmou que

à medida que o movimento evolui na
direção de um projeto de lei, a coisa
se complica, porque o projeto de lei é
prematuro, pelo fato de que não
existe documentação científica a
respeito do problema (do
esquerdismo nas escolas e
universidades). Você não pode
começar um debate legislativo sem
ter o debate científico primeiro. Acho
que colocaram a carroça na frente
dos bois. Nós não temos uma visão
quantitativa da hegemonia comunista
no ensino, e ainda estamos na
esfera do argumento retórico. ${ }^{48}$

A declaração do tradutor da tese do marxismo cultural para a audiência brasileira demonstra que o "argumento retórico" que ajudou a difundir no país assumiu vida própria, chamando atenção para 0 que acontece no interior da sala de aula. Assim como a bibliografia daquele curso da Universidade Stanford foi capaz de desavir os EUA nos anos 1980, sob a alegação de que o livro de uma indígena guatemalteca seria uma ameaça à civilização ocidental, a livre circulação de ideias no espaço escolar parece representar hoje também um risco para segmentos da população

\footnotetext{
${ }^{48}$ Ver:

https://catracalivre.com.br/cidadania/olavo-decarvalho-critica-escola-sem-partido/. Acesso em: 20 fev. 2020.
} 
brasileira e uma oportunidade para diferentes projetos políticos.

Como vimos, o movimento criado por Miguel Nagib nasceu em um momento no qual a aliança ultraliberalconservadora, hoje aparentemente hegemônica na cena política brasileira, ainda ensaiava sua reativação. Foi na sucessão de acontecimentos que se deram a partir do segundo mandato de Lula que a pauta pôde se consolidar, sendo decisivamente impulsionada pela roupagem moralizante que fez do ESP uma plataforma de denúncia à suposta presença da "ideologia de gênero" nas escolas (MIGUEL, 2016). Esse elemento-chave para o êxito do movimento, em suas implicações com o fortalecimento das posições conservadoras no país, aponta para as oscilantes concepções de laicidade que estruturam as políticas educacionais brasileiras.

Vale lembrar que, pelo Decreto 7.107/2010, o próprio governo Lula concedeu benefícios jurídicos à Igreja Católica no país e predispôs uma perigosa abertura ao modelo de ensino religioso confessional nas escolas públicas. Esse acordo firmado com a Santa Sé foi um dos mais recentes eventos de uma longa história de transações que fizeram o cristianismo, e mais especialmente o catolicismo romano, ser naturalizado como referência de religiosidade e moralidade no cotidiano das escolas brasileiras. No período imperial, por exemplo, a oferta da disciplina obrigatória "Instrução Religiosa" sancionava a difusão didática dos simbolismos e valores católicos, em detrimento de outros credos e perspectivas morais.

Tal presença foi combatida no contexto de elaboração de nossa primeira Constituição, promulgada em 1891, no qual a determinação da laicidade do ensino público no Brasil resultou de uma ampla oposição: "liberais e maçons, que bem podiam ser católicos, se juntaram aos protestantes e aos positivistas na formação de uma frente laica" (CUNHA, 2017, p. 213). Esse feito, que Cunha qualificou como nossa primeira onda laica, tornou-se objeto de diversos retrocessos ao longo do século XX. Segundo o autor, apenas com a Assembleia Nacional Constituinte, na década de 1980, o Brasil assistiria a uma segunda onda laica, fundamentada nos anseios 
inclusivos e pluralistas que pautaram a elaboração da Carta Cidadã.

O contexto em que esses ideais parecem se colocar sub judice forma o pano de fundo da apresentação do ESP em uma capital como Belo Horizonte. Cabe notar, a partir do que vimos, como as diferentes partes do conflito se colocam como defensoras da Constituição de 1988, mobilizando a linguagem dos direitos fundamentais para defender causas distintas.

É assim que o projeto de $l \mathrm{ei}^{49}$, evocando a Convenção Americana sobre Direitos Humanos, postula sobre "o direito dos pais dos alunos a que seus filhos recebam a educação religiosa e moral que esteja de acordo com as suas próprias convicções", sendo vetado ao professor "o direito de dizer aos filhos dos outros o que é a verdade em matéria de religião ou moral”. Já em sua apreciação do projeto $^{50}$, a então vereadora Áurea Carolina enfatizaria $\mathrm{o}$ direito do

\footnotetext{
${ }^{49}$ Ver:

http://cmbhsildownload.cmbh.mg.gov.br/silinter net/servico/download/documentoVinculado?id Documento=2c907f765c8e8a2d015cc59a860d 1711. Acesso em: 4 set. 2020.

${ }^{50}$ Ver:

http://cmbhsildownload.cmbh.mg.gov.br/silinter net/servico/download/documentoVinculado?id Documento=2c907f765f786e7f015f9cb0eb181 062. Acesso em: 4 set. 2020.
}

estudante aprender e do professor ensinar, havendo "limites do direito dos pais no que concerne à escolha do tipo de educação que deverá ser ministrada aos seus filhos". Como se vê, o que parece estar em jogo é uma disputa a respeito do sujeito dos direitos fundamentais: se, por um lado, prevalecem as liberdades garantidas aos indivíduos, sejam eles docentes ou alunos, ou se, por outro, é o personagem da família que detém a prerrogativa de definir sozinho o horizonte da formação dos menores de idade.

Não deve assim parecer um gesto casual o surgimento de um ramo de atuação dedicado à noção de "Família" dentre as funções do Ministério dos Direitos Humanos, no quadro do governo Bolsonaro. Sob o comando da advogada e pastora Damares Alves, a pasta parece acenar àquele imperativo de produzir entendimentos do que são o país e sua sociedade, organizado pelo ideal da uniformidade política, cultural e religiosa. Em 2019, na cerimônia de lançamento da Frente Parlamentar em Defesa do Homeschooling (ensino domiciliar), a Ministra defendeu a adoção da prática, já que seria "direito 
PAULA, Leandro de; IGLESIAS, João Victor. "Meu filho, minhas regras": o caso do Escola sem partido em Belo Horizonte. PragMATIZES - Revista Latino-Americana de Estudos em Cultura, Niterói/RJ, Ano 11, n. 20, p. 136-161, março 2021.

dos pais decidir sobre a educação dos seus filhos, é uma questão de direitos humanos" ${ }^{\prime 1}$. Aos esforços de pesquisa cabe então o acompanhamento de como as concepções das liberdades fundamentais - dentre elas as de ensinar e aprender - tendem a continuar a ser desafiadas em controvérsias públicas, nas quais a figura da família desponta como novo sujeito privilegiado de direitos.

\section{Referências bibliográficas}

AZEVEDO, Reinaldo. Por uma Escola sem Partido. Veja, São Paulo, 19 nov. 2008. Disponível em:

https://veja.abril.com.br/blog/reinaldo/p or-uma-escola-sem-partido/. Acesso em: 15 jul. 2020.

\section{BEDINELLI, Talita. A educação} brasileira no centro de uma guerra ideológica. El País Brasil, Política. 26 de junho de 2016. Disponível em: http://brasil.elpais.com/brasil/2016/06/2 2/politica/1466631380_123983.html?id extern o_rsoc=FB_CM ?rel=mas. Acesso em: 15 jul. 2020.

BRIDI, Carla; BERALDO, Paulo. O que é 'marxismo cultural' e por que ele é debatido? Estadão, São Paulo, p. 1-2, 11 abr. 2019. Disponível em: https://politica.estadao.com.br/noticias/ geral,o-que-e-marxismo-cultural-e-porque-ele-e-debatido,70002786682. Acesso em: 21 fev. 2020.

\footnotetext{
${ }^{51}$ Ver: https://www.gov.br/mdh/ptbr/assuntos/noticias/2019/abril/ministradamares-defende-educacao-domiciliar-comoum-direito-humano. Acesso em: 6 set. 2020.
}

\section{BUCKEL, Sonja; FISCHER-}

LESCANO, Andreas. Reconsiderando Gramsci: hegemonia no direito global. Rev. direito GV, São Paulo, v. 5, n. 2, p. 471-490, dez. 2009.

CARVALHO, Olavo. Do marxismo cultural. O Globo, Brasil, 8 jun. 2002. Disponível em:

http://olavodecarvalho.org/domarxismo-cultural/. Acesso em: 20 mar. 2020.

GALLEGO, Ester; ORTELLADO, Pablo; MORETTO, Márcio. Guerras culturais e populismo antipetista nas manifestações por apoio à Operação Lava-Jato e contra a Reforma daPrevidência. Em Debate, v. 9, n. 2, p. 35-45, ago. 2017.

HUNTER, James Davison. Culture Wars: the Struggle to define America. New York: Basic Books, 1991.

KAMEL, Ali. O que ensinam às nossas crianças. O Globo, 18 de setembro de 2007. Disponível em:

http://www.alikamel.com.br/artigos/que -ensinam-nossas-criancas.php. Acesso em: 20 ago. 2020.

LEITE, Vanessa. "Em defesa das crianças e da família": Refletindo sobre discursos acionados por atores religiosos "conservadores" em controvérsias públicas envolvendo gênero e sexualidade. Sex., Salud Soc. (Rio J.), Rio de Janeiro, n. 32, p. 119-14, ago 2019.

MIGUEL, Luis Felipe. Da "doutrinação marxista" à "ideologia de gênero"Escola Sem Partido e as leis da mordaça no parlamento brasileiro. Revista Direito e Práxis, Rio de Janeiro, v. 7 , ed. 15 , p. 590-621, 2016. 
MOURA, Fernanda. "Escola Sem

Partido": Relações entre Estado, Educação e Religião e os impactos no ensino de história.

Dissertação(Mestrado Profissional em História). Universidade Federal do Rio de Janeiro, Rio de Janeiro, 2016.

NAGLE, Angela. Kill All Normies:

Online Cultural Wars From 4chan and Tumblr to Trump and the Alt-Right.UK: Zero Books, 2017.

NUNES, Rodrigo. Todo lado tem dois lados. Revista Serrote, junho de 2020. Disponível em:

https://www.revistaserrote.com.br/2020 /06/todo-lado-tem-dois-lados-porrodrigo-nunes/. Acesso em: 20 ago. 2020.

PRATT, Mary Louise. Me llamo Rigoberta Menchú y sus críticos en el contexto norteamericano. Debate Feminista, v. 20, p. 177-197, outubro 1999.

ROCHA, Camila. "Menos Marx mais Mises": Uma gênese da nova direita brasileira(2006-2018).Tese (Doutorado em Ciência Política). Universidade de São Paulo, São Paulo, 2018.

VENTURINI, Tommaso. Building on faults: how to represent controversies with digital methods. Public Understanding of Science, 21 (7), p. 796-812, 2012.

ŽIŽEK, Slavoj. Aula ministrada em 10 de novembro de 2018 na Cambridge Union. Vídeo disponível em: https://www.youtube.com/watch?v=YnVf1-1 hrU. Acesso em: 16jul. 2020. 